\title{
SUPPLEMENTARY FILE 1
}

\section{Section 1: Principles of participatory systems modelling}

Planning stakeholder engagement - the selection of stakeholders to include as participants, the functions they will have, their level of involvement, and at what phases of the model development process they will be involved, all require careful consideration [24, 43]. The domains of influence, skills and knowledge that each stakeholder, or group of stakeholders, will bring to the process also needs to be taken into account, together with the knowledge and skills within the modelling team, to ensure the right expertise is available to guide model development [50], prevent 'blind spots', and avoid the introduction of disciplinary bias.

Being aware of social and group dynamics - it is important to consider the motivations and intentions of stakeholders in engaging in a participatory modelling process as well as the motivations and intentions of modellers (and other professionals) in proposing the involvement of stakeholders [20]. Inclusivity in the selection of participants should be advocated for to facilitate the contribution of diverse perspectives. The social dynamics within the participant group need also to be managed, including, for example, how powerful stakeholders and special interest groups might permit, facilitate, or encourage other actors to participate, or alternatively, how they might prevent them from participating [20].

Having flexibility in the process - involving participants from the commencement of the process, defining the goals of the study and the model scope, purpose, and timeframe is important [20, 21$]$. Participation in the model development process itself thus becomes an important and productive part of the project. Unexpected changes in priorities should be expected and accommodated (where possible) within the process, particularly when the changes result from learning from the model $[20,21]$. The priorities and focus of a commissioning agency or the project funders may have a greater influence in determining model purpose and timeline for completion, but flexibility in incorporating participant preferences and priorities within those boundaries are encouraged. Stakeholder motivation is important for the success of projects, and stakeholders may be demotivated if they are forced into a predefined protocol or procedure [21]. Striking a balance between having the project too "predetermined", i.e., too highly structured to achieve meaningful engagement, and too "unstructured", i.e., too broad and lacking focus, is important to ensure that the model can be delivered within policy relevant timeframes.

Maximising transparency and openness - being open both scientifically and socially is valuable throughout the process. Understanding the range of assumptions stakeholders hold, and designing models (and model interfaces) that facilitate the testing of alternative assumptions and their implications encourages stakeholders to integrate the models into decision making processes [21]. Throughout model development, collaborative decision making should be emphasised, allowing participants to contribute, for example, to prioritising interventions to be integrated into the model and debating which data sources are most appropriate to parameterise the model. Models need to be validated against real world data across a range of outcomes, well documented (with key assumptions, research, and data sources used made explicit), and maintained in such a way that would make them available for future use and modification if required [21].

Iterating and refining - participatory systems modelling needs to be iterative, collaborative and agile $[10,20,21]$. The active engagement of participants through the iterative development process facilitates a sense of ownership of the model where participants may come to see it as "their" model rather than a "black box" model that may not be well understood by them [10]. Participant input also helps to prevent modellers making naive assumptions that may reflect a lack of domain expertise [10] or knowledge of the social and policy environment of a given region, and lead to representation of an idealised version of a system rather than a contextually grounded one.

Encouraging learning and managing uncertainty - Models are always evolving as new evidence becomes available and new policy applications arise, and uncertainty is an important ongoing consideration [20, 21]. Models can help quantify and manage uncertainty by better understanding points of high leverage or high sensitivity in the system being modelled. Lack of completeness of data 
should not be used to justify a decision not to model as methods, such as the active engagement of stakeholders to guide the parameterisation and check the logical consistency of models, explicit analysis of uncertainty and sensitivity, can be used even where there are data gaps [10]. Models have significant potential to assist learning and good decision making through the participatory process by bringing together best evidence, data and knowledge and consolidating and testing a shared hypothesis $[25,32]$.

\section{Section 2: Core materials list for workshop activities}

\section{Workshop 1- conceptual mapping exercise}

This activity requires:

- $\quad$ pre-printed and laminated elements of the model structure;

- large sheets of paper e.g., butchers' paper;

- post-it notes;

- paper tape,

- marker pens;

- audio recorders; and

- large table with space for participants to move around to view the system from different perspectives

\section{Workshop 2 - intervention mapping exercise}

This activity requires:

- $\quad$ pre-printed model structure on large A0 sized paper (for entire model) or A2 sized paper (for the separate model components) - the former is preferred but the latter is an appropriate alternative if $\mathrm{AO}$ sized paper is not available;

- intervention questions printed on large paper for small group work;

- $\quad$ marker pens;

- audio recorders (1 per group); and

- large tables with space for participants to move around to view the printed systems model architecture from different perspectives.

\section{Workshop 3 - user interaction with the model}

This activity requires:

- computers with modelling software installed and model running;

- tables arranged to facilitate small group interaction; and

- $\quad$ sufficient printed screenshots of the user interface pages to allow participants to provide feedback on nomenclature, ranges on dials and sliders, and highlight where additional information should be provided to aid the interpretation of findings and improve general interface usability. 


\section{Section 3: Workshop agendas}

\section{Systems modelling- Workshop 1 Agenda \\ Right care, first time, where you live}

DATE:

TIME:

VENUE:

\begin{tabular}{|c|c|c|}
\hline Time & Ifem & Facilitator/s \\
\hline 08:30-09:00 & Arrival, registration and tea/coffee & \\
\hline 09:00-09:45 & $\begin{array}{l}\text { Welcome and overview of the Program aims and } \\
\text { Objectives } \\
\text { - Acknowledgement of Country / } \\
\text { Acknowledgement of lived experience } \\
\text { - Welcome by host organisation } \\
\text { - Icebreaker activity } \\
\text { - Overview and aim of the project }\end{array}$ & $\begin{array}{l}\text { Lead domain expert } \\
\text { Local elder/ Local lived } \\
\text { experience representative } \\
\text { Host organisation } \\
\text { representative } \\
\text { Systems Modelling Manager }\end{array}$ \\
\hline $09: 45-10: 15$ & $\begin{array}{l}\text { Session 1: Introduction to dynamic simulation } \\
\text { modelling } \\
\text { - What is dynamic simulation modelling and how } \\
\text { can it help? } \\
\text { - Questions }\end{array}$ & Systems Modelling Manager \\
\hline $10: 15-10: 45$ & $\begin{array}{l}\text { Session 2: Introduction to the architecture, tools and } \\
\text { symbols of systems dynamics } \\
\text { - Introducing the tools \& symbols } \\
\text { - Unfurling the simple model infrastructure } \\
\text { - Questions }\end{array}$ & Systems Modeller \\
\hline $10: 45-11: 15$ & $\begin{array}{l}\text { Session 3: Defining the system and outcomes of } \\
\text { interest } \\
\text { - Defining the problem and outcomes } \\
\text { - Discussion }\end{array}$ & $\begin{array}{l}\text { Lead Domain Expert } \\
\text { Systems Modelling Manager }\end{array}$ \\
\hline $11: 15-11: 30$ & Morning Tea & \\
\hline $11: 30-12: 30$ & $\begin{array}{c}\text { Session 4: Participatory mapping exercise } \\
\text { - Interactive pathway mapping }\end{array}$ & Systems Modelling Manager \\
\hline $12: 30-13: 30$ & Lunch & \\
\hline $13: 30-14: 30$ & Session 4 cont: Participatory mapping exercise & Systems Modelling Manager \\
\hline 14:30-15:15 & $\begin{array}{c}\text { Session 5: Prioritising the interventions of interest } \\
\text { - Interventions of interest activity }\end{array}$ & Systems Modelling Manager \\
\hline $15: 15-15: 45$ & $\begin{array}{l}\text { Session 6: Economics, next steps and data contribution } \\
\text { - Introduction to the role of economic analysis } \\
\text { - Next steps and identifying data sources }\end{array}$ & $\begin{array}{c}\text { Economics Lead } \\
\text { Systems Modelling Manager } \\
\text { Lead Domain Expert } \\
\end{array}$ \\
\hline $15: 45-16: 00$ & $\begin{array}{l}\text { Session 7: Concluding session } \\
\text { - Closing remarks by host organisation }\end{array}$ & $\begin{array}{l}\text { Host organisation } \\
\text { representative }\end{array}$ \\
\hline
\end{tabular}




\section{Systems modelling- Workshop 2 Agenda}

Right care, first time, where you live

DATE:

TIME:

VENUE:

\begin{tabular}{|c|c|c|}
\hline Time & Item & Facilitator/s \\
\hline 08:30-09:00 & Arrival, registration and tea/coffee & \\
\hline 09:00-09:30 & $\begin{array}{l}\text { Welcome back and recap from workshop } 1 \\
\text { - Acknowledgement of Country/ Acknowledgement of } \\
\text { lived experience } \\
\text { - Recap of the last workshop and progress since } \\
\text { previous workshop }\end{array}$ & $\begin{array}{l}\text { Local elder/ Local lived } \\
\text { experience representative } \\
\text { Systems Modelling Manager }\end{array}$ \\
\hline 09:30-10:30 & $\begin{array}{l}\text { Session 1: Presentation of the system dynamics model } \\
\text { - Model structure to date }\end{array}$ & Systems Modeller \\
\hline $10: 30-10: 45$ & Morning tea & \\
\hline $10: 45-11: 15$ & $\begin{array}{l}\text { Session 2: Intervention mapping } \\
\text { - Review of interventions and prioritsation }\end{array}$ & $\begin{array}{l}\text { Systems Modelling Manager } \\
\text { and Local Domain expert }\end{array}$ \\
\hline $11: 15-12: 15$ & $\begin{array}{l}\text { Session 3: Intervention mapping exercise } \\
\text { - Mapping intervention mechanisms against core } \\
\text { model structure }\end{array}$ & Systems Modelling Manager \\
\hline $12: 15-13: 15$ & Lunch & \\
\hline $13: 15-14: 15$ & Session 3 cont: Intervention mapping exercise & Systems Modelling Manager \\
\hline 14:15-15:00 & $\begin{array}{l}\text { Session 4: Economic component } \\
\text { - Overview of aims and intended approach }\end{array}$ & Economics lead \\
\hline 15:00-15:15 & Session 5: Concluding session & Site representative \\
\hline
\end{tabular}




\section{Systems modelling- Workshop 3 Agenda}

Right care, first time, where you live

DATE:

TIME:

VENUE:

\begin{tabular}{|c|c|c|}
\hline Time & Ifem & Facilitator/s \\
\hline 08:30-09:00 & Arrival, registration and tea/coffee & \\
\hline 09:00-09:20 & $\begin{array}{l}\text { Welcome back and recap from workshop } 2 \text { and } \\
\text { progress update } \\
\text { - Acknowledgement of Country/ Acknowledgement of } \\
\text { lived experience } \\
\text { - Recap of the last workshop and progress since } \\
\text { previous workshop }\end{array}$ & $\begin{array}{l}\text { Local elder/ Local lived } \\
\text { experience representative } \\
\text { Systems Modelling Manager }\end{array}$ \\
\hline 09:20-10:20 & $\begin{array}{l}\text { Session 1: Demonstration of the systems dynamic } \\
\text { model } \\
\text { - Present the model structure and logic } \\
\text { - Model demonstration } \\
\text { - To explain where participant feedback has been } \\
\text { used to refine the model. }\end{array}$ & Systems Modeller \\
\hline 10:20-10:35 & Morning Tea & \\
\hline 10:35-11:35 & $\begin{array}{l}\text { Session 2: User interaction with the model } \\
\text { - Interact with model interface in groups } \\
\text { - Questions, feedback and recommendations }\end{array}$ & \\
\hline $11: 35-12: 05$ & $\begin{array}{l}\text { Session 3: Health economics } \\
\text { - Presentation on status of economic analysis } \\
\text { - Discussion / feedback }\end{array}$ & Economics Lead \\
\hline \multirow[t]{2}{*}{$12: 05-12: 20$} & $\begin{array}{l}\text { Session 4: Concluding session: Next steps, closing } \\
\text { remarks and feedback }\end{array}$ & Systems Modeller \\
\hline & Lunch (optional) & \\
\hline
\end{tabular}

